\title{
SER E AGIR PARA UMA ARTICULAÇÃO ENTRE ANTROPOLOGIA E ÉTICA EM LUDWIG FEUERBACH
}

\author{
Adriana Veríssimo Serrão1
}

\begin{abstract}
RESUMO
O presente artigo procura articular os conceitos de antropologia e de ética em Ludwig Feuerbach, inquirindo se devem ser identificados ou distinguidos, isto é, se a Antropologia enquanto filosofia do homem integral contém já implicitamente uma ética, ou se a ética, que é o seu correlato, não será também o seu efectivo aprofundamento. Duas considerações preliminares têm de ser feitas: uma diz respeito ao conceito de antropologia, que não é unívoco e sofre manifesta evolução ao longo da trajectória intelectual de Feuerbach; a outra remete para o facto de a tematização desenvolvida da ética ser tardia e ocorrer duas décadas após a fundamentação da filosofia da sensibilidade. Num primeiro momento, recuperamos alguns aspectos da ligação entre concepção do homem e concepção da moral no primeiro Feuerbach, quando ambas são perspectivadas sob a ideia de razão, gerando a circularidade entre razão humana e homem racional. Seguidamente consideramos as diversas "antropologias" trabalhadas no contexto da psicologia da religião, sobretudo em A Essência do Cristianismo, obra na qual se cruzam distintas perspectivas do humano e que terá conduzido Feuerbach a elaborar uma filosofia do homem integral. Esta só ganha fundamentação plena nos escritos de 1843, a par da ontologia da Sinnlichkeit, sendo aí a essência do homem concreto explicitada através dos princípios do sensualismo e do altruísmo. Nos escritos tardios, sobretudo em Sobre o espiritualismo e o materialismo, em particular na referência à liberdade da vontade, de 1866, identificamos um núcleo de convergência - o princípio da felicidade enquanto potenciação do ser - e outros de divergência, no quadro da distinção entre ser, agir e responsabilidade moral. Finalizaremos enunciando algumas reflexões de Feuerbach que superam a tendência para o antropocentrismo constitutiva da natureza humana, tais como os direitos políticos das mulheres e a extensão da comunidade ética aos entes não-humanos.
\end{abstract}

Palavras-chave: Feuerbach, antropologia, ética, direitos das mulheres, direitos da natureza.

\begin{abstract}
This article aims to articulate the concepts of anthropology and ethics in Ludwig Feuerbach, inquiring whether they should be identified or distinguished, that means, if anthropology as a philosophy of the whole man has already implicitly an ethical response, or if the ethics, which is its correlatum, brings new perspectives. Two preliminary considerations have to be made: one concerns the concept of anthropology, which is not univocal and suffers an obvious evolution through the intellectual trajectory of Feuerbach; the other refers to the fact that the developed thematization of ethics occur two decades after the foundation of the philosophy of sensibility. At first, we recover some aspects of the connection between conception of man and conception of morality in the first Feuerbach, when both are envisaged under the idea of reason, causing the circularity between human reason and rational man. Then we consider the various "anthropologies" worked in the context of the psychology of religion, especially in The Essence of Christianity, in which intersect different visions of human and have led Feuerbach to develop a philosophy of the whole man. This awareness is fullfilled in the writings of 1843, along with the ontology of Sinnlichkeit, where the essence of the concrete man is explained through the principles of sensuality and altruism. In later writings, especially in About spiritualism and materialism, particularly in reference to the freedom of the will, von 1866, we identify a main convergence - the principle of happiness as potentiation of being - and other aspects of divergence in the context of the distinction between to be, to act and moral responsibility. At last, we comment some thoughts of Feuerbach that overcome the
\end{abstract}

1 Professora no Departamento de Filosofia da Faculdade de Letras da Universidade de Lisboa. Presidente do Conselho Científico da Internationale Gesellschaft der Feuerbach-Forscher (Berlin, 1997; Münster, 2004). 
tendency toward anthropocentrism that is constitutive of human nature, such as the political rights of women and the extent of ethical community to nonhumans.

Keywords: Feuerbach, anthropology, ethics, women's rights, nature's rights

\section{Razão e moral nos primeiros escritos}

Se bem que a inflexão humanizante da filosofia esteja presente desde a tese de doutoramento De ratione, una, universal infinita, de 1828, colocando a razão incarnada no género humano (Gattung) em lugar do Espírito da filosofia hegeliana, tal protagonização genérica não é ainda suficiente para identificar uma preocupação antropológica. Decorrendo a essência do homem da sua participação num único género - "a unidade dos homens nada mais exprime [...] do que a unidade da própria razão" (GW 1, 96) -, Feuerbach deriva facilmente desta identidade os modos que permitem ao indivíduo suprimir a condição de ser finito e alcançar a sua humanidade: unicamente aqueles pelos quais ultrapassa uma existência confinada à espácio-temporalidade empírica e anula o Eu como realidade substancial. A forma conceptual da racionalidade concretiza-se numa comunidade de seres pensantes na qual pensar não implica estar fisicamente junto a outros, mas torna possível que cada um seja todos os outros.

Ao longo dos anos 30 o jovem pensador exalta o poder do pensamento, que liga os indivíduos entre si libertando-os do respectivo isolamento e elogia um tipo de vida dedicada à cultura, na qual cada um se liberta de si-mesmo e dos seus interesses particulares. A reversibilidade entre razão e comunidade reflecte-se também numa concepção de moral despojada de elementos pessoais e privados, guiada pela objectividade da sã razão natural e visando a desejável integração da consciência de si individual na consciência universal. Tendo por guia a sã razão natural, capaz de colher a realidade na sua objectividade e de fundar uma visão transparente do mundo, celebrado é o ideal do homem destituído de individualidade pessoal e privada:

Nós trazemos em nós mesmos um mundo objectivo e um mundo subjectivo. E não somos outra coisa senão os órgãos deste mundo objectivo, o qual representamos e realizamos, decerto segundo a nossa constituição, de modo razoável ou insano, adequado ou falso, claro ou obscuro, perfeito ou atrofiado. O próprio espírito é, porém, o mundo objectivo em nós, independente e não afectável por nós. (Kritik des "Anti-Hegels". Zur Einleitung in das Studium der Philosophie, GW 8, 102).

\begin{tabular}{|c|c|c|c|c|}
\hline QRovista Dialectus & Ano 2 & n. 6 & Janeiro - Agosto 2015 & p. $47-59$ \\
\hline
\end{tabular}


À subjectividade religiosa, associada ao enclausuramento na interioridade e ao egoísmo interesseiro, é contraposta a união do amor universal e de atitudes intelectuais, como a admiração pela beleza natural, traços complementares da vida teorética, modelada por uma rigorosa disciplina que subordina ao pensamento tanto a esfera da acção quanto a dos sentimentos privados. Recorde-se o relevo concedido nesta fase ao filósofo como homem universal, bem como às figuras do escritor e do cientista da natureza, modelos do homem completo e perfeito (vollkommener Mensch), que através do livro e do conhecimento alcançam um plano de comunicação espiritual referida à Humanidade inteira:

Tais indivíduos são indivíduos-norma do género (GattungsNormalindividuen), seres singulares, cada um dos quais é um grande ser comum (Gemeinwesen), pontos centrais da Humanidade, poderes soberanos nos quais o espírito humano faz convergir todas as suas forças, plenitude e realidade. (Abälard und Helö̈se, oder der Schriftsteller und der Mensch, GW 1, 574).

Será no contexto da atenção de Feuerbach à psicologia da religião que surgem os primeiros indícios de uma viragem antropológica, por outras palavras, a compreensão de traços do humano que lhe são constitutivos mas não são determináveis pela razão pensante. Um momento assinalável encontra-se em 1838 no ensaio que dedica ao fenómeno do milagre (Über das Wunder), no qual descortina uma certa propensão da sensibilidade, aliada ao desejo e à imaginação, para transformar factos sensivelmente observados em acontecimentos com significado miraculoso - "Os milagres são fenómenos psicológicos, ou melhor, antropológicos; têm o seu fundamento no homem" -, concluindo que "o milagre contradiz a razão [...]. Mas não contradiz o homem em geral." (GW 8, 320).

Que a humanidade não seja inteiramente resolúvel na racionalidade pensante, e que haja disposições da sensibilidade não convergentes em operações do conhecimento objectivo é um dos fios condutores da filosofia da religião. Na interpretação deste fenómeno marcante da existência humana Feuerbach adopta uma posição não refutativa, mas hermenêutica, seguindo o método "genético-crítico" que pesquisa aqueles mecanismos da subjectividade que levam o homem à criação de uma realidade suprasensível povoada de entidades supra-humanas e regida por leis que contrariam as do mundo natural. Esta inquirição das profundezas da subjectividade, que não podem ser

\begin{tabular}{|c|c|c|c|c|}
\hline Q Povista Dialectus & Ano 2 & n. 6 & Janeiro - Agosto 2015 & p. $47-59$ \\
\hline
\end{tabular}


catalogadas como meramente irracionais ou ilusórias, traz à luz outras dimensões do humano que solicitam à filosofia que repense tanto a essência da razão quanto a essência humana.

Não será por isso de estranhar que nenhuma outra obra como A Essência do Cristianismo (Das Wesen des Christentums) use tantas vezes a palavra "antropologia". Mas, quando analisada de fio a pavio, não é possível isolar nela uma concepção única de antropologia, porque se entrelaçam pelo menos três.

Uma é a antropologia explícita que consta da Introdução, ponto de chegada da teoria da essência perfilhada desde a tese de doutoramento: a essência humana é um complexo de poderes fundamentais - a razão, a vontade e o coração -, propriedade do género mas não do indivíduo, como um universal-transversal que está no indivíduo mas acima da sua individualidade. A segunda é uma antropologia implícita que decorre da tradução dos predicados divinos, mais propriamente divinizados, em predicados humanos. Os sucessivos capítulos são outras tantas análises destes atributos fundamentais, que confirmam a tese segundo a qual "a teologia é antropologia": o que o homem diz de Deus diz indirectamente de si mesmo, ou em Deus o homem não se revela senão a si mesmo.

A terceira, e decerto a mais decisiva no percurso intelectual de Feuerbach, é uma antropologia que podemos designar de latente, porque acede a zonas do ser humano que não cabem na visão anteriormente defendida de uma racionalidade auto-consciente e transparente. Dimensões como o desejo e a imaginação, e sobretudo o coração (Herz) intervêm decididamente para suscitar ao filósofo que considere o homem enquanto totalidade. Particularmente significativa é a distinção entre ânimo (Gemüt) e coração

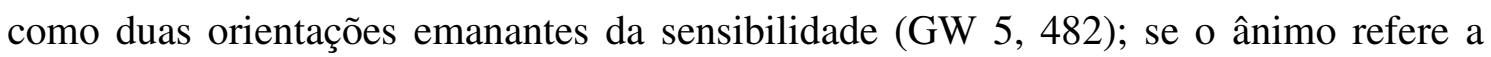
sensibilidade ensimesmada, egoísta e doentia, o coração deixará de estar subordinado ao pensamento para assumir a paridade com "a cabeça", modos complementares de abertura ao mundo. Particularmente relevante nesta progressiva tomada de consciência da necessidade de pensar o humano real não apenas enquanto portador de faculdades (poderes) universais, mas integrando a também a incompletude e a fragilidade é esta passagem da Aplicação Conclusiva:

Demonstrámos que a religião afirma incondicionalmente não apenas as forças da essência humana, mas também as fraquezas, os desejos mais subjectivos do coração humano... (GW 5, 443).

\begin{tabular}{|c|c|c|c|c|}
\hline Q Povista Dialectus & Ano 2 & n. 6 & Janeiro - Agosto 2015 & p. $47-59$ \\
\hline
\end{tabular}


É o homem como problema que se coloca agora à filosofia, mas a resolução deste problema implica, por sua vez, a transformação da filosofia de assunto estritamente académico, operando com categorias escolares, numa causa da Humanidade, conduzida por uma atitude realista, imersa na vida, radicada na "nãofilosofia" onde encontra doravante um novo fundamento e novos princípios para o seu filosofar.

\section{A unidade de ser e agir no quadro da filosofia da Sinnlichkeit}

Os princípios da filosofia da sensibilidade estabelecidos nas Teses provisórias para a reforma da filosofia e nos Princípios da filosofia do futuro, de 1843, fundam uma visão unitária do mundo, tanto na ontologia, instituindo a indivisibilidade do real, quanto na antropologia, instituindo a indivisibilidade do ser humano. É por de mais evidente, nos parágrafos em que a sequência histórica da velha filosofia é apresentada, que nenhuma das orientações precedentes - panteísmo, empirismo, idealismo e lógica especulativa - estaria em condições de resolver a unidade e totalidade do humano, sendo que todas elas conduziram a desumanizações e cisões: quer à abstracção, idealizando o homem segundo o modelo do filósofo, quer a dualismos insuperáveis, opondo nele a existência (o que é) à essência (o que deveria ser). Uma nova antropologia fundada numa nova ontologia evita a idealização, sendo que a essência não é deduzida de nenhum conceito prévio, mas é captada na própria existência dos homens de carne e osso.

Por um lado, a realidade ou existência sensível é a infinita multiplicidade dos existentes singularmente diferenciados; por outro, a essência do ser sensível repousa na reversibilidade das suas faces, activa e passiva, a cuja conjunção se deve toda a dinâmica do ser. Em termos ontológicos, existência equivale a coexistência; todo ser é ser em relação, simultaneamente activo e receptivo, sujeito e objecto. Em termos antropológicos, o homem é ser incarnado (um corpo-sujeito), no mundo e com os outros, na relação recíproca de Eu e Tu: "Eu sou eu - para mim - e ao mesmo tempo tu - para o outro." (Grundsätze der Philosophie der Zukunft §33, GW 9, 317).

A ideia de homem integral (ganzer Mensch) como medida da razão - afastando qualquer visão parcial do humano e recusando veementemente a distinção clássica entre o racional e o antropológico - contém já implicitamente uma ética mínima, sendo que

\begin{tabular}{|l|l|l|l|l|}
\hline Q Ronista Dialectus & Ano 2 & n. 6 & Janeiro - Agosto 2015 & p. 47-59 \\
\hline
\end{tabular}


recusa de um só gesto as morais abstractas, dualistas e em geral o valor moral por estas atribuído à renúncia, ao sacrifício e à ascese. Mas precisamente enquanto ética mínima permanece inexplorada nas suas efectivas implicações para uma filosofia moral. Talvez seja por isso que vinte anos após ter consolidado a filosofia da Sinnlichkeit Feuerbach aborde explicitamente a questão da fundamentação da moral ("o homem como princípio da moral"), convertendo o princípio do indivíduo-indiviso em base de uma ética eudemonista. Sendo todos os princípios da nova filosofia formulados como conjunções duplas, também o princípio supremo (incondicionado) da moral - a felicidade enquanto potenciação de ser - é duplicado através do sensualismo e do altruísmo e sintetizado como felicidade do $\mathrm{Eu}$ e do $\mathrm{Tu}$, ou felicidade social (gesellige) e comunitária (gemeinschaftliche), ou ainda, noutra formulação, como conciliação e dupla implicação de egoísmo e comunismo.

\begin{abstract}
A felicidade não concentrada numa e mesma pessoa, mas repartida entre diversas pessoas, englobando eu e tu, não a felicidade unilateral, mas a felicidade bilateral ou omnilateral, é o princípio da moral. (Über Spiritualismus und Materialismus, besonders in Beziehung auf die Willensfreiheit, GW 11, 73).
\end{abstract}

Contudo, se a filosofia da sensibilidade sustenta uma antropologia e esta conduz a uma moral da felicidade conjunta, ela não é ainda suficiente para responder à questão ética subjectiva - como devo agir? -, porque se a antropologia é descritiva de traços humanos universais, a ética é necessariamente prescritiva e tem em conta a situação concreta daquele que individualmente age. Para seguir esta linha de desenvolvimento, importa considerar primeiramente a teoria geral do agir e identificar seguidamente quais os requisitos do agir moral.

$\mathrm{Na}$ unidade das dimensões que compõem a integralidade humana o agir é uma extensão do ser, não determinado nem cindido por um qualquer plano de dever-ser, nem proveniente de uma especial faculdade racional. O ser humano é expansivo e desenvolve-se em continuidade; o agir é o próprio ser em movimento, mobilizado por impulsos, desejos e afecções, quando se dirige para a alteridade mundana e pessoal na qual satisfaz necessidades e carências, numa palavra, na qual se vai realizando. Não havendo faculdades separadas, também não existirá uma capacidade especial vocacionada para determinar as acções: a acção é o agir de um ser inteiro, o acto de um sujeito integral, um ser no mundo e referido aos outros; por isso, tal é, assim age.

\begin{tabular}{|l|l|l|l|l|}
\hline Q Ponista Dialectus & Ano 2 & n. 6 & Janeiro - Agosto 2015 & p. 47-59 \\
\hline
\end{tabular}


E esta liberdade não existe numa faculdade particular, a vontade, como tão-pouco esta universalidade [existe] numa faculdade particular, a faculdade de pensar, a razão - esta liberdade, esta universalidade estende-se pelo seu ser inteiro. (Grundsätze der Philosophie der Zukunft §54, GW 9, 336.

A introdução da passividade como princípio ontológico da Sinnlichkeit tem, entre muitas outras funções, a de superar a alternativa entre condicionamento e liberdade. O homem pode ser livre mesmo no seio da necessidade natural, não sendo o condicionamento contraditório com a liberdade do agir, uma vez que se trata sempre de uma autodeterminação da vontade mas no interior de uma determinação natural independente da vontade do homem. Na sua teoria da acção, Feuerbach procura superar a clivagem entre liberdade e determinismo, que tem o seu ponto de partida numa coexistência inicial de liberdade e condicionamento, para se consumar como coexistência de contingência e necessidade. O paradoxo do agir humano de conter tanto a liberdade como o condicionamento, e de os conter em cada acto singular, tem uma especial implicação na esfera da filosofia moral como filosofia interpessoal.

O adjectivo moral não é aplicável ao ser do indivíduo. Este não é moral pelo seu modo de ser, pois nenhum acto o esgota a ponto de o poder definir moralmente; tampouco pode dizer-se moral pela intenção interior que o move, pois a contingência é um limite inultrapassável do ser humano e, reconhecida como tal, retira ao agir todo o carácter absoluto. Mas enquanto o agir produz actos, e um acto, qualquer que seja, possui implicações sobre outros indivíduos, torna-se legítimo considerar a distinção de ser e de agir como paralela à distinção entre o lado subjectivo e o lado objectivo da acção.

\section{Da teoria da acção à ética: ser, agir e responsabilidade}

Ser e agir são o mesmo, mas desdobram-se, na medida em que cada sujeito representa um duplo papel: Eu e Tu; daí que: ser é ser para mim, agir é ser para outro. No ser há total identificação do sujeito consigo, mas o agir põe-no como que fora dele, autor de uma acção que passa a estar lançada no mundo, objectivada, submetida ao juízo moral, abrindo-se todo o problema da responsabilidade moral por actos que não provêm

\begin{tabular}{|c|c|c|c|c|}
\hline Q Povista Dialectus & Ano 2 & n. 6 & Janeiro - Agosto 2015 & p. $47-59$ \\
\hline
\end{tabular}


de uma liberdade total, mas pelos quais se tem de ser responsável desde que afectem a esfera do outro.

Quem matou é sem dúvida um assassino, mas este ser linguístico não esgota o meu ser real, pois é apenas uma expressão desta minha acção. O meu ser é a minha referência a mim mesmo; o meu agir a minha referência a outros; mas precisamente aos outros só lhes diz respeito, só cai na esfera da responsabilidade, o que sou para eles, isto é, o que faço, não o que eu sou para mim. (Über Spiritualismus und Materialismus, GW 11, 100).

Se a condição de finito impõe limitações ao meu ser, sou, pelo contrário, inteiramente responsável pelo acto agido que intervém no outro causando-lhe bem ou mal, isto é, intervindo positiva ou limitativamente na expressão do impulso dele para a felicidade. Autonomia e hetero-responsabilização coincidem. Somos responsáveis pelo que fazemos, na medida em que devemos responder perante o outro por aquelas acções pelas quais intervimos na sua esfera e pelas consequências delas resultantes:

O ser é silencioso, despretensioso, recolhido em si, satisfeito em si; mas o agir é afável e loquaz, provoca alarido para o prazer ou o incómodo dos outros. (Ibidem, GW 11, 100).

Daí que, na ética feuerbachiana, mesmo não sendo livre, no sentido de possuir um poder de decisão interior e incondicionado, o homem seja inteiramente responsável pelo seu agir, isto é, pelo seu ser para o outro. Numa palavra: o ser para si (a relação de cada um a si) permanece no âmbito do extra-moral; o imperativo ético da felicidade não se pode converter num Sê bom, como adequação a um conjunto de regras às quais o ser individual se deveria moldar. Mas quando o agir é o ser para outros, então sobre a acção recai a valoração e o ajuizamento e, ao mesmo tempo, a responsabilidade moral:

O homem sente-se responsável apenas por aquilo pelo que é responsabilizado também pelos outros, pelo menos enquanto possuem bom-senso, só é responsabilizado por aquilo que faz, não por aquilo que é. (Ibidem, GW 11, 99-100).

Assim, numa ética concreta, a responsabilidade moral é imanente à experiência, mas não anterior a ela. Ela brota face aos outros com os quais convivemos e não tem sentido independentemente deles. Não sendo responsáveis pelo nosso ser, enquanto seres privados, temos todavia de nos sentir responsáveis e de sermos efectivamente res-

\begin{tabular}{|c|c|c|c|c|}
\hline Q Povista Dialectus & Ano 2 & n. 6 & Janeiro - Agosto 2015 & p. $47-59$ \\
\hline
\end{tabular}


ponsabilizados pela acção que é o nosso ser público, o nosso ser comum. Se não estamos em condições de prever todo o alcance e implicações dos nossos actos, o mal destes actos desvendar-se-á, tal como o seu bem, no confronto com o outro e tendo em conta os efeitos produzidos. Por isso, mesmo que haja desculpa pelo modo de agir, não há qualquer desculpa face à acção consumada. A autonomia e objectividade da acção salvaguardam a total autoria dos actos e a responsabilização pelos seus resultados.

Feuerbach retira todo o peso moral da intenção privada ou do carácter pessoal para o depositar inteiramente, e sem restrições, sobre os resultados da acção. A objectividade e a responsabilidade determinam a configuração da acção moral: negativamente, como a acção que não faz mal; positivamente, como a acção que faz bem. A vontade moral é a vontade que quer fazer o bem (Ibidem, GW 11, 80).

Feuerbach confere-lhe uma formulação normativa, imperativa e universal, independente de todo o conteúdo de que venha a revestir-se. Há assim, e inevitavelmente, uma antinomia implícita entre a imensa vulnerabilidade do agir humano e a total responsabilidade que lhe é exigida. Antinomia essa que uma moral humana não pode anular, sem deixar justamente de ser humana, mas que apenas pode explicitar na aceitação conjunta de dois princípios, ambos imperativos: o princípio ético que afirma: Sê feliz; o princípio moral que afirma: Faz o bem.

$\mathrm{Na}$ mediação entre a felicidade pessoal e a felicidade do outro intervém ainda a consciência moral. Ela é a instância interiorizada do outro, a representante do "outro eu no eu", sem a qual o agir cairia inevitavelmente num constante experimentalismo de tentativas e erros. É a voz do ofendido que precede, como instância limitadora, os nossos actos e deve no momento de agir orientar o nosso ser. A expressão normativa da ética - conciliar o meu direito (eu quero ser feliz) e o direito do outro (eu quero ser feliz) - são por fim convertidos em direito e dever, mas ambos presentes no mesmo sujeito: o direito do outro é meu dever.

O meu direito é a minha tendência à felicidade legalmente reconhecida, o meu dever é a tendência à felicidade do outro, que me determina ao seu reconhecimento. (Ibidem, GW 11, 79).

O dever é uma auto-negação, mas que me é ordenada pelo amor de si do outro. (Ibidem GW 11, 75).

A distinção de ser e agir impõe-se do ponto de vista do exercício ético concreto: o agir de cada indivíduo sempre situado em situações diferentes, irrepetíveis e

\begin{tabular}{|c|c|c|c|c|}
\hline Q Povista Dialectus & Ano 2 & n. 6 & Janeiro - Agosto 2015 & p. $47-59$ \\
\hline
\end{tabular}


imprevisíveis. O último pensamento de Feuerbach amplia uma filosofia da existência com traços marcadamente existenciais.

\section{A ética para além da antropologia}

Uma via de responder à questão - até que ponto a ética completa a antropologia ou a excede? - encontra-se na distinção entre ser, agir e dever para com os outros atrás explanada. Uma perspectiva complementar decorre da distinção entre o realismo teórico e o idealismo prático, dois ângulos de abordagem nos quais uma mesma filosofia que nunca deixa de ser prática, enraizada na vida e emergindo da não-filosofia, se pode colocar no seu propósito de recuperação do homem integral. Feuerbach associa a filosofia teórica à filosofia do real, que se mantém no estrito plano da existência e é regida pelo princípio do realismo. Trata-se, no fundo, de uma formulação variante que sintetiza a vertente fundamentadora e engloba todo o processo de incarnação da razão nas estruturas do humano concreto seguindo como método a passagem do objecto real ao objecto pensado. A filosofia prática, por sua vez, é associada ao plano da ideia e do ideal e é regida pelo princípio do idealismo, comprovando que o homem integral é para Feuerbach um processo, e não um dado acabado, um caminho de efectivação futurizante, capaz de acolher questões epocais e novas formas de consciência social e cívica.

Eu sou idealista apenas no domínio da filosofia prática, isto é, aqui não faço das limitações do passado e do presente limitações da Humanidade, do futuro [...]; mas no domínio da filosofia teórica propriamente dita, vale para mim [...] apenas o realismo, o materialismo na acepção indicada. (Das Wesen des Christentums (B), GW 5, 15).

Tendo em conta a tendência progressiva, transformadora e histórica, recolhemos neste último ponto duas temáticas que complementam a antropologia realista, o primeiro de índole sócio-política, o segundo que inscreve Feuerbach como precursor da ética da natureza dos nossos dias. Em ambos está presente a ideia de comunidade como coexistência includente de todos os seres sensíveis, em paridade e conservando as respectivas diferenças individuais.

O primeiro radica na ideia de género humano enquanto contém a diferenciação de sexos, um tópico amplamente desenvolvido em Das Wesen des Christentums

\begin{tabular}{|l|l|l|l|l|}
\hline Q Ponista Dialectus & Ano 2 & n. 6 & Janeiro - Agosto 2015 & p. 47-59 \\
\hline
\end{tabular}


dirigido contra a assexualidade do Deus metafísico e retomado, por exemplo, na Réplica a Max Stirner, contrapondo ao Eu-Único destituído de determinações a relação dual homem-mulher como operador e multiplicador de humanidade (GW 9, 434). A conversão da diferenciação antropológica do género humano em indivíduos-homens e indivíduos-mulheres numa exigência da igualdade político-jurídica entre sexos ocorre, embora não suficientemente tematizada nas obras publicadas, em termos muito esclarecedores nos últimos anos de vida de Feuerbach:

Embora eu tenha constantemente defendido e reconhecido a diferença dos sexos como uma diferença essencial, e não apenas corporal mas também espiritual, nunca concluí daí a inferioridade do espírito feminino. Homem e mulher não são apenas diferentes pelo corpo, mas também pelo espírito; mas seguir-se-á desta diferença a subordinação, a exclusão das mulheres das ocupações espirituais e universais, e não apenas domésticas? (Carta a W. Bolin, 1870, SW XIII, 363).

A não incompatibilidade entre o realismo (teórico) da diferença e o idealismo (prático) da igualdade fica patente na recepção positiva de Feuerbach à questão emergente no seu tempo dos direitos das mulheres, nomeadamente a reivindicação do direito de voto e de intervenção na vida política, como uma tarefa do futuro:

Em suma, a emancipação da mulher é uma causa e questão da justiça e igualdade universais, a que presentemente a Humanidade aspira, uma aspiração da qual ela se vangloria, mas que será frustrada se dela se excluir a mulher. (Ibidem, 362-363).

Outro tópico a ter em conta concerne ao próprio ideal de comunidade, que é ampliada a seres não-humanos, também eles providos de direitos, numa surpreendente extensão da esfera dos deveres do homem. Também neste ponto se assiste ao cruzamento, mas não à coincidência, da ontologia (e antropologia) da sensibilidade com a ética.

A ontologia oferece já um caminho seguro para a dignificação de todos os entes, quando atribui a qualquer existente, humano, artificial ou natural, o estatuto comum de sujeito, como tal possuidor de valor intrínseco e não instrumental: "Ser significa ser sujeito, significa ser para si." (Grundsätze \$25, GW 9, 304). Do reconhecimento do estatuto de sujeito, ser para si dotado de autonomia, decorre a reciprocidade de todos os

\begin{tabular}{|l|l|l|l|l|}
\hline Govista Dialectus & Ano 2 & n. 6 & Janeiro - Agosto 2015 & p. 47-59 \\
\hline
\end{tabular}


existentes numa visão paritária e equiparada do mundo constituído de seres semelhantes, uma comunidade como república destituída de hierarquias e desníveis.

Contudo, a reflexão irá aprofundar-se quando dedica alguns escritos, nomeadamente as duas versões de Das Wesen der Religion (A essência da religião), de 1846, à compreensão das religiões naturais de feição animista. Ao inquirir a génese do processo de antropomorfização da natureza que lhes é próprio, detecta um mecanismo enraizado no comportamento ancestral do homem, a saber, a tendência para dominar a realidade não-humana. Esta tendência universalmente presente desde as formas arcaicas até níveis mais elaborados da cultura e da civilização torna evidente um modo constitutivo do agir humano que não é pacífico e vem introduzir um factor de perplexidade numa antropologia que se afigurava como harmoniosa e destituída de conflitos. Trata-se de uma propensão natural, arreigada, para o domínio sobre a natureza, que tanto pode assumir a modalidade de uma subtil antropomorfização dos entes naturais como chega a atingir as mais requintadas formas de violência. Feuerbach chega mesmo a esclarecer a distinção entre aquele antropocentrismo que é inevitável em todo o conhecimento e comportamento humanos e aquele outro que assume um grau de dominação e de subjugação do outro:

\begin{abstract}
O homem pensa tudo sob a figura da sua própria essência; ele é o ser absoluto, de onde deriva e explica tudo. Assim como representa as coisas, assim elas são para ele, em si; da verdade de si mesmo, ele não duvida; o que ele faz pressupõe uma intenção - portanto, também o que a Natureza faz. O seu entendimento é para ele o ser supremo; tal como subordina fisicamente a Natureza, também a subordina espiritualmente, teoreticamente, ao seu entendimento, transforma-se em senhor e legislador da Natureza. (Das Wesen der Religion, Erste Fassung, ed. Tomasoni, 284).
\end{abstract}

É evidente que esta tendência, por estar tão profunmente inscrita no ser do humano e por não se tratar de um conjunto de actos esporádicos ou próprios de alguns indivíduos, por ser uma constante antropológica, reclama uma consciência autocrítica limitadora do poder que dela resulta. Numa intuição que vai muito para a frente do seu tempo, com uma voz discordante no contexto de um culturalismo extremo que atingia a própria filosofia, Feuerbach diagnostica na separação de homem e natureza um sintoma de declínio:

\begin{tabular}{|c|c|c|c|c|}
\hline QRovista Dialectus & Ano 2 & n. 6 & Janeiro - Agosto 2015 & p. $47-59$ \\
\hline
\end{tabular}


O nosso mundo, e de modo algum apenas o político e social, mas também o nosso mundo espiritual e erudito, é um mundo invertido. $\mathrm{O}$ triunfo da nossa cultura, da nossa civilização, residiu na sua maior parte apenas no afastamento e desvio, o maior que foi possível, da Natureza, o triunfo da nossa ciência, da nossa cultura erudita no afastamento e desvio, o maior que foi possível, da verdade simples e evidente. (Vorlesungen über das Wesen der Religion, GW 6, 118).

Daí que a ética para com a natureza reconhecendo a moralidade intrínseca da natureza como um todo e os direitos de cada um dos seres naturais seja uma das vias anunciadas da ética do futuro fundada num comportamento justo: tratar a natureza como Tu é condição de um habitar ético na natureza:

Mas o que vale para o homem em face do homem vale também para ele em face da natureza. Ele não é apenas o eu, mas também o tu da natureza. (Carta a Julius Duboc, 27 de Novembro de 1860, SW XIII, 254).

\section{Referências Bibliográficas}

GW = Ludwig Feuerbach. Gesammelte Werke, ed. Werner Schuffenhauer, Berlin, Akademie Verlag, 1967 ss.

SW = Ludwig Feuerbach. Sämtliche Werke, ed. Wilhelm Bolin und Friedrich Jodl, Stuttgart 1903-1911; vol. XI, 2. ${ }^{\text {a }}$ ed. (1959-1960), vols. XII-XIII (1964).

Das Wesen der Religion (Erste Fassung), publicada em Francesco Tomasoni, Ludwig Feuerbach e la natura non umana. Ricostruzione genetica dell' Essenza della religione con pubblicazione degli inediti. Firenze, La Nuova Italia, 1986.

\begin{tabular}{|l|l|l|l|l|}
\hline Q Ponista Dialectus & Ano 2 & n. 6 & Janeiro - Agosto 2015 & p. 47-59 \\
\hline
\end{tabular}

